\title{
Characteristics and recognition of guardians living in the urgent protective action planning zone of the Genkai Nuclear Power Plant, Saga Prefecture, Japan who wished to receive pre-distribution stable iodine for their children
}

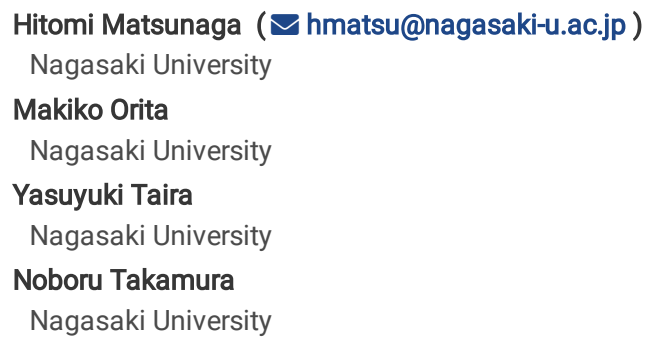

Research Article

Keywords: Stable iodine, Pre-distribution, The urgent protective action planning zone, Child

Posted Date: May 5th, 2021

DOI: https://doi.org/10.21203/rs.3.rs-453210/v1

License: () (1) This work is licensed under a Creative Commons Attribution 4.0 International License. Read Full License 


\section{Abstract}

Purpose区The aim of this study was to clarify the characteristics and the awareness of nuclear prevention measures including prophylactic stable iodine (SI) of guardians of 0 - to 6-year-old children living in the urgent protective action planning zone (UPZ) of the Genkai Nuclear Power Plant (GNPP), Japan.

Methods冈Of these 1172 guardians, 973 responded that they wished to receive pre-distribution of stable iodine (PDSI) and 199 did not wish to receive PDSI.

Results: Logistic regression analysis showed that the following items were independently associated with guardians who wished to receive PDSI for their children: thinking that pregnant women should take prophylactic SI (odds ratio [OR]=6.57, 95\% confidence interval [CI]: $4.62-9.35 ; \mathrm{p}<0.01$ ); wishing to participate in a lecture about the health effects of radiation exposure $(\mathrm{OR}=1.99,95 \% \mathrm{Cl}: 1.40-2.82 ; \mathrm{p}<0.01)$; thinking that $\mathrm{SI}$ can prevent exposure from all radionuclides $(\mathrm{OR}=1.93,95 \% \mathrm{Cl}: 1.24-2.99 ; \mathrm{p}<0.01)$; awareness of SI before the study $(\mathrm{OR}=1.91,95 \% \mathrm{Cl}: 1.35-3.00 ; \mathrm{p}<0.01)$; and anxiety about prophylactic SI for their children $(\mathrm{OR}=0.33,95 \% \mathrm{Cl}: 0.20-0.55 ; \mathrm{p}<0.01)$. The GNPP was one of the nuclear power plants in Japan that resumed operations after the Fukushima Dai-ichi Nuclear Power Plant accident in 2011.

Conclusion: These results suggest that some residents have incomplete knowledge about nuclear prevention, including SI. Therefore, it is essential to educate residents and communicate the health risks of radiation exposure with residents living around nuclear power plants. Furthermore, it is important to train specialists to educate and communicate with residents to prepare for a nuclear accident.

\section{Background}

On March 11, 2011, the Great East Japan Earthquake caused extensive damage to Tokyo Electric Power Company's Fukushima Daiichi Nuclear Power Station (FDNPS) that resulted in the release of various radionuclides, including iodine-131, cesium-134, and cesium-137, into the atmosphere [1-4]. In response to the accident, the Japanese national government and the Fukushima prefectural government ordered a mandatory evacuation of residents who lived within about a 20-km radius from the FDNPS, and the residents who lived within a 20- to 30-km radius of the FDNPS to shelter indoors depending on the radiation dose of their residential area and the status of the FDNPS accident [5,6]. As a result of the nuclear accident, mandatory evacuation from their hometowns in Fukushima near the FDNPS was required for 110,000 residents [1, 2]. However, confusion regarding the evacuation orders in the early phase and a variety of disruptive information about the health effects of radiation from the accidents resulted in the voluntary evacuation of approximately 164,000 residents from their hometowns, even though they lived more than $20 \mathrm{~km}$ from the FDNPS. As of December 2020, a total of 43,000 residents, including voluntary evacuees from Fukushima Prefecture, remained in other towns in Fukushima or in other prefectures [6]. In addition, immediately after the accident there was confusion regarding prophylactic stable iodine (SI) among the public because insufficient information was provided by the national and local Japanese governments, and because of the popular misconception that SI is a silver bullet that protects against harm from radiation exposure [7]. Several local governments established a mandatory evacuation zone and distributed SI to their residents; however, systematic prophylaxis was not implemented because of time pressure, and insufficient information and explanations were provided about SI and iodine thyroid blocking (ITB) [8, 9].

In response to the nuclear accident, the Nuclear Regulation Authority of Japan established the "Nuclear Emergency Response Guidelines" to provide an appropriate and smooth nuclear emergency response for the vast numbers of residents living around nuclear power stations [10]. The guidelines established the priority areas where protective measures will be implemented in the event of an emergency at a nuclear power station. The precautionary action zone (PAZ) is an area within a radius of $5 \mathrm{~km}$ from the nuclear power plant in which evacuation is conducted proactively before the release of radioactive materials The urgent protective action planning zone (UPZ) is the area within a radius of $30 \mathrm{~km}$ outside the PAZ, where preventive protection measures, such as sheltering and then evacuation and temporary relocation are to be carried out in nuclear accident stages or according to the radiation air dose rate. Generally, distribution of SI and provision of prophylactic SI to UPZ residents are based on the judgement of the Nuclear Regulation Authority regarding the result of the emergency monitoring of air radiation doses after the release of radionuclides from a nuclear power plant accident [11, 12]. However, recently, pre-distribution of SI (PDSI) for UPZ residents has been started by some administrations to some persons located in areas where it is difficult to receive SI at a public shelter, school, etc., when they need to evacuate urgently from their residences to other areas. Since 2019, five of 21 administrations located within $30 \mathrm{~km}$ from a nuclear power plant have started PDSI for UPZ residents under 40 years of age [13]. Moreover, all local governments in areas within which a nuclear power station is located are required to plan nuclear prevention measures and be responsible for holding nuclear prevention drills or annual meetings for residents, administration staff, and nuclear-emergency response professionals. Local governments are also responsible for providing SI supplements, instructing residents in the PAZ on how to perform SI prophylaxis, and for providing residents in the UPZ who are younger than 40 years of age with PDSI [11].

Kyushu Electric Power Co., Inc.'s Genkai Nuclear Power Plant (GNPP) is located in Genkai Town, Saga Prefecture, Japan (Fig. 1). The GNPP has four reactors, two of which have been restarted since the FDNPS accident [14], and PDSI was started from 2019 for UPZ residents who have applied for it and are under 40 years of age [15]. The population in the PAZ around the GNPP, i.e., people living in Genkai Town and Karatsu City, is 8,126 (2,876 households), and that in the UPZ is 254,700 (103,330 households), i.e., people living in one town and seven cities in Saga, Nagasaki, and Fukuoka Prefectures. The UPZ of the GNPP in Saga Prefecture covers an area that includes Genkai Town, with a population of 2,292 people (692 households), Karatsu City, with a population of 11,148 people (48,638 households), and Imari City, with a population of 56,063 (22,911 households) [16].

Under the current Nuclear Regulation Authority guidelines, PDSI is implemented to all residents under the age of 40 in the PAZ; in the UPZ, PDSI is only implemented to those under the age of 40 years who request it. In our previous study, we focused and clarified the characteristics of guardians in the PAZ around the GNPP who received PDSI. Among the 247 respondents, living in the PAZ (odds ratio [OR]: 4.48, 95\% confidence interval [CI]: $2.43-8.24$ ), having an awareness of preferential iodine thyroid blocking in children (OR: $3.33,95 \% \mathrm{Cl}: 1.78-6.22)$, and awareness of the booklet regarding SI published by the local government (OR: $2.53,95 \% \mathrm{Cl}$ : 1.37-4.68) were independently associated with having received PDSI for their children. In addition, when we asked guardians living in the PAZ their reasons for not having received PDSI, $40.2 \%$ indicated anxiety about the side effects of SI, $23.5 \%$ distrusted of the effectiveness of SI, and $15.7 \%$ thought the procedures for receiving SI were complicated [unpublished observation]. However, we did not investigate the characteristics of residents

Page $2 / 10$ 
living in the UPZ who wished to receive PDSI for their children. Therefore, the guardians of 0 to 6-year-old children living in the vicinity of the GNPP in Japan were surveyed to determine the characteristics of those who wished to receive PDSI and their awareness of nuclear prevention measures including prophylactic SI. The aim of this study was to determine the characteristics of guardians living in the UPZ who wished to receive PDSI for their children and to evaluate their understanding of nuclear prevention measures in the UPZ.

\section{Methods \\ Study participants}

This study was conducted from January to June 2020 in two municipalities (Karatsu City and Imari City) located within 30 km from the GNPP in Saga Prefecture, Japan (Fig. 1). This study was approved by the ethics committee of the Nagasaki University Graduate School of Biomedical Sciences (No. 19083003). Informed consent was obtained from individual participant through the instructions about ethical considerations of the study.

A self-administered questionnaire regarding SI and recognition of nuclear prevention measures was distributed to approximately 3000 guardians with children through the 26 kindergartens in both cities in the UPZ, and responses were obtained from 1863 (response rate: $62.1 \%$ ). After excluding incomplete responses, data were obtained from 20 (1.1\%) guardians who lived within $5 \mathrm{~km}$ from the GNPP [PAZ], 1172 (65.7\%) who lived within $30 \mathrm{~km}$ of the GNPP [UPZ], 229 (12.8\%) who lived more than $30 \mathrm{~km}$ from the GNPP, and 364 (20.4\%) whose distance from the GNPP was unknown. In the study, the data of 1172 guardians (1011 mothers and 161 fathers) who lived within 5 to $30 \mathrm{~km}$ [UPZ] were included in the analysis.

\section{Data collection}

The self-administered questionnaire asked guardians whether they wished to receive PDSI for their children. Those who wished to and did not wish to receive PDSI were defined as "Group 1" and "Group 2", respectively. Furthermore, we illustrate them to belief explanation about effects of SI such as "Stable iodine tablets prevent thyroid exposure from a substance called radioactive iodine for about 24 hours. It is stockpiled in municipal government buildings so that it can be distributed immediately in the event of a nuclear disaster. There is a sweet jelly that can be taken to protect an unborn baby even during pregnancy and is easy to take even for newborns." And we asked whether they wished to receive prophylactic SI for their children during a nuclear emergency in "yes/no" question.

Demographic factors, including sex, age $(<30,30-39,40-49$, and $\geq 50$ years), number of children under 18 years of age, social factors, and distance from the GNPP to their house (PAZ, UPZ, > $30 \mathrm{~km}$, and unknown), were also included in the questionnaire. In addition, "yes/no" questions regarding whether they had participated in a nuclear emergency drill, whether they had known about SI before the study, whether they had known of a public shelter near their house to evacuate to during a nuclear emergency, and whether they had used a social network service (SNS) to collect information about radiation exposure were also asked. Furthermore, whether they wished to participate in a lecture about the health effects of radiation exposure, whether they felt anxious about prophylactic SI for their children, whether they thought that pregnant women should also receive prophylactic SI, whether they thought that sheltering is useful to reduce the dose of radiation exposure, and whether they thought that SI could prevent exposure from all radionuclides were also asked. For these questions, respondents were asked to choose one of the following four responses: "yes", "I think so", "I don't think so", or "no". We classified "yes" and "I think so" responses as "yes", and "no" and "I don't think so" responses as "no".

\section{Statistical analysis}

Differences between Group 1 and Group 2 were evaluated using chi-squared tests. Then, factors independently associated with the wish to receive PDSI were identified using binominal logistic regression analysis. We classified ages of $<30-39$ years as $\leq 39$ years, and $40-\geq 50$ years as $\geq 40$ years. In the binomial logistic regression analysis, the following factors were included as covariates because the p-values obtained from the chi-squared tests for these items were < 0.05: "thought that pregnant woman also should receive prophylactic SI"; "wish to participate in a lecture about the health effects of radiation exposure"; "thought that SI can prevent exposure from all radionuclides"; and "had known about SI before the study". All p-values < 0.05 were considered significant. The statistical analysis was performed using IBM SPSS Statistics (version 19; (SPSS Japan, Tokyo, Japan).

\section{Results}

Of the 1172 guardians who responded to the questionnaire and were living in the UPZ, 973 and 199 were classified into Group 1 and Group 2 , respectively. Of the 973 guardians in Group 1, 310 (31.9\%) had not known about SI before the study, 620 (63.7\%) felt anxious about prophylactic SI for their children, and 992 (84.6\%) wished to receive prophylactic SI for their children during a nuclear emergency. Of the 992 guardians who wished to receive prophylactic SI for their children, 371 (37.4\%) had not known about SI before the study, and 667 (67.2\%) felt anxious about prophylactic SI for their children during a nuclear emergency (Fig. 2). Figure 3 shows awareness of nuclear prevention measures and SI. Overall, 461 (39.3\%) guardians responded that sheltering is not useful to reduce the dose of radiation exposure, 396 (33.8\%) responded that SI could prevent exposure from all radionuclides, and 296 (25.2\%) responded that pregnant women should also take prophylactic SI during a nuclear emergency.

Of the 1172 guardians, 1011 (86.3\%) were female, 227 (19.4\%) had one child, 493 (42.1\%) had two children, and 452 (38.6\%) had three or more children. Regarding the age of the guardians, $121(10.3 \%)$ were $<30$ years, $729(62.2 \%)$ were $30-39$ years, $315(26.9 \%)$ were $40-49$ years, and $7(0.6 \%)$ were $\geq 50$ years (table.1).

As shown in Table 2, the guardians in Group 1 were significantly more interested in participating in a lecture about the health effects of radiation exposure $(\mathrm{n}=$ $593 ; 60.9 \%)$ compared with those in Group $2(n=83 ; 41.7 \% ; p<0.01)$. The guardians in Group 1 also showed significantly more interest in prophylactic SI for their children during a nuclear emergency $(n=912 ; 93.7 \%)$ compared with those in Group $2(n=80 ; 40.2 \% ; p<0.01)$. In addition, the guardians in Group 1 had 
known significantly more about SI before the study $(n=620,63.7 \%)$ than those in Group $2(n=96 ; 48.2 \% ; p<0.01)$. Moreover, the guardians in Group 1 felt significantly more anxious about prophylactic SI for their children $(n=663 ; 68.1 \%)$ than those in Group $2(n=178 ; 89.4 \% ; p<0.01)$. The guardians in Group 1 were significantly more likely to think that pregnant women should also take prophylactic SI $(n=804 ; 82.6 \%)$ compared with those in Group 2 ( $n=72 ; 36.2 \%$; $p$ <.01). In addition, the guardians in Group 1 were significantly more likely to think that sheltering is useful for reducing the dose of radiation exposure ( $\mathrm{n}=$ $611 ; 62.8 \%)$ than those in Group $2(n=101 ; 50.7 \% ; p<0.01)$, and that SI could prevent exposure from all radionuclides $(n=364$ [37.4\%] vs. $n=31$ [15.6\%], respectively; $p<0.01)$. No significant differences were found between Groups 1 and 2 in terms of age of the guardians $(<39$ years $[72.4 \%]$ vs. $\geq 40$ years [73.4\%]; $p=0.42)$, participation in a nuclear emergency drill $(18.8 \%$ vs. $16.1 \% ; p=0.42)$, knowledge of a public shelter near their house to evacuate to during a nuclear emergency $(41.8 \%$ vs. $40.2 \% ; p=0.37)$, or use of an SNS to collect information about radiation exposure $(20.6 \%$ vs. $21.6 \% ; p=0.40)$.

As shown in Table 3, the results of the logistic regression analysis showed that the following factors were independently associated with the wish to receive PDSI (Group 1): thought that pregnant women should also take prophylactic SI (odds ratio [OR] = 6.57, 95\% confidence interval [CI]: 4.62-9.35; $p<0.01$ ); wish to participate in a lecture about the health effects of radiation exposure (OR $=1.99,95 \% \mathrm{Cl}: 1.40-2.82 ; \mathrm{p}<0.01)$; thought that SI can prevent exposure from all radionuclides $(\mathrm{OR}=1.93,95 \% \mathrm{Cl}: 1.24-2.99 ; \mathrm{p}<0.01)$; had known about SI before the study $(\mathrm{OR}=1.91,95 \% \mathrm{Cl}$ : $1.35-3.00 ; \mathrm{p}<0.01)$; and felt anxiety about prophylactic SI for their children (OR $=0.33,95 \% \mathrm{Cl}: 0.20-0.55 ; \mathrm{p}<0.01)$.

\section{Discussion}

In Japan, active provision of information about nuclear prevention measures and PDSI to residents who live around a nuclear power plant has begun based on the experience of the FDNPS accident in 2011 [17]. The present study identified the characteristics of the guardians living 5-30 km (UPZ) from a nuclear power plant who wished to receive PDSI (Group 1) or did not wish to receive PDSI (Group 2) and their awareness of nuclear prevention measures including prophylactic SI for pregnant woman and their young children living near the GNPP. The results showed that about $40 \%$ of the guardians had not known about $\mathrm{SI}$, and about $60 \%$ of the guardians had not known of a public shelter near their house to evacuate to during a nuclear power plant emergency. This study showed that the guardians who lived 5-30 km from a nuclear power plant were not familiar with SI and nuclear prevention measures.

In Japan, when an emergency occurs at a nuclear power plant, all PAZ residents should take prophylactic SI and then begin evacuation before release of radionuclides into the atmosphere. On the other hand, UPZ residents should first shelter in their house or a public shelter, and then begin evacuation depending on the status of the nuclear plant accident and the air dose rate in their residential area [10].

Therefore, the recommendation of the World Health Organization (WHO) for a nuclear emergency is that, in areas further away from a nuclear power plant emergency situation, PDSI to households is not considered feasible, and stocks of SI should be stored strategically at, for example, schools, hospitals, pharmacies, fire stations, police stations, and civil defense centers such as public shelters [18].

However, the present study showed that of $40 \%$ guardians thought that sheltering is not useful for reducing the radiation exposure dose. Sheltering with closed windows and any forced ventilation shut off is not completely effective for avoiding radiation exposure, though sheltering is a relatively simple protective measure to reduce internal and external radiation exposure from various radionuclides including radioactive iodine in the early phase of a nuclear accident [19]. In a study, the Japanese government showed that, compared to staying outdoors, sheltering in a standard wooden house can reduce external radiation exposure by about $60 \%$. In addition, a standard rebar house can reduce external radiation exposure by about $90 \%$ compared to staying outdoors. Furthermore, internal exposure can be reduced by about $30 \%$ compared to staying outdoors, regardless of the type of house materials without ventilation [20]. In the case of a nuclear emergency, stand-alone protective action, such as only prophylactic SI, should not be considered. It is important to give residents a strong message about the effectiveness of sheltering and recommend that they prepare to stay in their house in the case of a nuclear disaster [19].

In the present study, $83 \%$ of guardians wished to receive PDSI, and $84.6 \%$ wished to receive prophylactic SI for their children in a nuclear emergency. However, of the guardians who wished to receive PDSI, 31.9\% did not know about SI before the study, and 63.7\% felt anxious about prophylactic SI for their children. Similarly, of the guardians who wished to receive prophylactic SI for their children, $37.4 \%$ did not know about SI before the study, and $67.2 \%$ felt anxious about prophylactic SI for their children. These results show conflict between the guardian's awareness of SI, in other words, they wished to receive PDSI and also wished to receive prophylactic SI for their children during a nuclear emergency, but many of them felt anxious about prophylactic SI for their children.

The groups most likely to benefit from ITB are children, adolescents, and pregnant and breastfeeding women [21, 22], so priority should be given to children and younger adults. Side effects of SI are rare and include iodine-induced transient hyperthyroidism or hypothyroidism and allergic reactions [22, 23]. However, pregnant women and guardians of young children tend to be cautious about drugs in general, not only prophylactic SI [11]. The result of the regression analysis showed an independent association between guardians who wished to receive PDSI and those who thought that pregnant women should be given prophylactic SI in a nuclear emergency $(\mathrm{OR}=6.57)$. It is important to inform pregnant women and guardians of young children about the risks associated with prophylactic SI, including the benefits and side effects.

The present study showed that 33.7\% of the guardians thought that SI could prevent exposure from all radionuclides. Prophylactic SI can block or reduce the accumulation only of radioactive iodine in the thyroid [19]. Prophylactic SI within one to two hours before inhalation of and exposure to I-131 can block >90\% of thyroid uptake of I-131 [24]. Therefore, prophylactic SI is most effective in the first few hours of internal exposure. Nevertheless, there is a popular misconception that $\mathrm{SI}$ is a silver bullet against harm from radiation exposure. The WHO recommended training of health professionals and emergency workers in risk communication to raise public awareness (e.g., provision of leaflets, organizing campaigns) [18]. All local municipalities in which NPPs are located have a responsibility to perform nuclear prevention measures such as providing shelter, disseminating information concerning SI/ITB, and performing evacuation drills several times a year in preparation for the possibility of a nuclear emergency. However, the results of this study showed that limited numbers

Page $4 / 10$ 
of people (18.3\%) have participated in a nuclear emergency drill, possibly because of the low number of health communication professionals, a lack of opportunity to participate in such a drill, and low awareness of disaster prevention measures among local residents $[17,25,26]$. Education is key to disaster prevention, preparation, response, and recovery [27]. Our previous study revealed that $89.8 \%(467 / 520)$ of mothers residing near the Sendai Nuclear Power Plant of Kagoshima Prefecture, Kyusyu, Japan expressed anxiety regarding prophylactic SI for their children; this anxiety was positively correlated with their wish to consult an expert about SI and negatively correlated with having confidence about prophylactic SI for their children [28]. To maintain and enhance nuclear prevention measures including prophylactic SI for residents living 5-30 km from a nuclear power plant, it is essential to educate specialists who work in the field of health about countermeasures in the case of a nuclear accident in the local area.

There are several limitations in the study, First, the study was conducted only in the UPZ of the GNPP in Japan, one of the areas where PDSI was started to UPZ residents under 40 years of age in 2019 [13]. Since PDSI was not started in all UPZ areas in Japan, the study's results are not representative of the awareness of all UPZ residents. However, as soon as the PDSI system is ready, there will be pre-distribution spread over a wide area of the UPZ as well, and the present study might be considered as pioneering data regarding PAZ guardians of young children. Second, in our study of the UPZ area we did not collect data regarding the reasons for the guardians' anxiety about prophylactic SI for their children. Furthermore, we also did not collect data regarding the guardians' experiences or involvement in any disasters, including the FDNPS accident. These perceptions about SI and previous experience (or not) with disaster may have influenced the guardians' awareness of nuclear emergency measures. Lastly, this study included only residents who answered "within 30 km [UPZ]" from the GNPP. However, it is not clear that all guardians know the precise distance from their house to the GNPP. All data were collected from the kindergartens located within $30 \mathrm{~km}$ from the GNPP. Therefore, if a nuclear accident occurred in the GNPP, the study participants, the guardians or kindergarten staff should take the appropriate nuclear prevention measures to reduce radiation exposure. Thus, this study might provide effective baseline data for preparing preventive measures for nuclear disasters.

\section{Conclusions}

In conclusion, this is the first study to report the characteristics of guardians with children living in the UPZ, those who wished to receive PDSI or not, and their awareness of nuclear prevention measures after the experience of the FDNPS accident. Awareness that "pregnant women should also receive prophylactic SI", "want to participate in a lecture about radiation health effects", "SI can prevent exposure from all radionuclides", and "aware of SI before the questionnaire" were positively associated with the guardians who wished to receive PDSI. On the other hand, "felt anxious about prophylactic SI for their children" was negatively associated with guardians who wished to receive PDSI. The results of the present study suggest that it is important to train specialists to work in the UPZ and improve risk communication about nuclear prevention measures including SI to raise guardian awareness in preparation for a nuclear disaster.

\section{Declarations}

\section{Ethics approval and consent to participate.}

This study was approved by the ethics committee of the Nagasaki University Graduate School of Biomedical Sciences (No. 19083003). Informed consent was obtained from individual participant through the instructions about ethical considerations of the study. The study conducted is in accordance with declaration of Helsinki guidelines and regulations.

\section{Consent for publication.}

Consent for publication was obtained from the individual participant.

Availability of data and materials.

The datasets used and analyzed during the current study are available from the corresponding author on reasonable request.

\section{Competing of interests}

The authors declare that they have no Competing of interest.

\section{Funding}

This work was supported by KAKENHI Grant Number $20 \mathrm{H} 04017$.

\section{Authors' contributions}

$\mathrm{HM}$, participated in the conception of the study, collection and analysis of data and interpretation of the result, manuscript writing and revision. MO, YT participated in the conception of the paper, interpretation of the result, manuscript writing and revision. NT participated in the collection of data and manuscript revision.

\section{Acknowledgments}

We would like to thank all study participants and staff members of Karatsu City and Imari City in Saga prefecture in Japan.

\section{References}


1. International Atomic Energy Agency (IAEA). Report of Japanese Government to the IAEA Ministerial Conference on Nuclear Safety: The accident at TEPCO's Fukushima Nuclear Power Stations. Nuclear Emergency Response Headquarters of Japanese Government.

2011.https://japan.kantei.go.jp/kan/topics/201106/iaea_houkokusho_e.html. Accessed 23 Apr 2020.

2. International Atomic Energy Agency (IAEA). Additional report of the Japanese Government to the IAEA - The accident at TEPCO's Fukushima Nuclear Power Stations (Second Report). Nuclear Emergency Response Headquarters of Japanese Government.

2011.https://www.iaea.org/sites/default/files/japanreport120911.pdf\#search=\%27Additional+report+of+the+Japanese+Government+to+the+IAEA++TheAccessed 23 Apr 2020.

3. Zheng J, Tagami K, Watanabe Y, Uchida S, Aono T, et al. Isotopic evidence of plutonium release into the environment from the Fukushima DNPP accident. Scientific Reports. 2012; doi:10.1038/srep00304.

4. Ministry of Health, Labor and Welfare. Information on the Great East Japan Earthquake. 2011. https://www.jst.go.jp/pr/pdf/great_east_japan_earthquake.pdf. Accessed 23 Apr 2020.

5. International Atomic Energy Agency (IAEA). The Fukushima Daiichi Accident. 2015. https://www.iaea.org/publications/10962/the-fukushima-daiichiaccident. Accessed 23 Apr 2020

6. Fukushima Prefectural Govt. Fukushima Revitalization Station; Transition of evacuation designated zones. Fukushima, Japan. 2020. http://www.pref.fukushima.lg.jp/site/portal-english/en03-08.html. Accessed 23 Apr 2020.

7. Tokyo Electric Power Company. Investigation Committee on the Accident at the Fukushima Nuclear Power Station of Tokyo Electric Power Company Interim Report. 2020. http://www.cas.go.jp/jp/seisaku/ icanps/eng/interim-report.html. Accessed 23 Apr 2020.

8. Hatanaka T, Yoshida S, Ojino M, Ishii M. The communication of information such as evacuation orders at the time of a nuclear power station accident: recommendations for responses by the national government and electric power utilities to the "Information Disaster". Japan Med Assoc J. 2014;

9. https://.

10. Nishikawa Y, Kohno A, Takahashi Y, Suzuki C, Kinoshita H, et al. Stable iodine distribution among children after the 2011 Fukushima Nuclear Disaster in Japan: an observational study. J Clin Endocrinol Metab.2019. doi: https://doi.org/10.1210/jc.2018-02136.

11. Nuclear Regulation Authority. Nuclear Emergency Response Guidelines. (In Japanese). 2020. https://www.nsr.go.jp/data/000300735.pdf. Accessed 23 Apr 2020.

12. Nuclear Regulation Agency. For distribution and prophylaxis of stable iodine (In Japanese). 2019. https://www.nsr.go.jp/data/000024657.pdf. Accessed 23 Apr 2020.

13. Yoshida S, Ojino M, Ozaki T, Hatanaka T, Nomura K, et al. Guidelines for iodine prophylaxis as a protective measure: Information for physicians. JMJA. 2014. doi:

14. https://.

15. Cabinet Office, Policy Director of Japan. Conference documents regarding stable iodine, Minister of State for Nuclear Emergency Preparedness (in Japanese). 2020. https://www8.cao.go.jp/genshiryoku_bousai/pdf/08_sonota_anteiyouso.pdf. Accessed 23 Apr 2020.

16. Nuclear Regulation Authority. Genkai NRA Regional Office. 2020. https://www.nsr.go.jp/english/nuclearfacilities/genkai/index.html. Accessed 23 Apr 2020.

17. Saga Prefectural Government Office. Pre-distribution of stable iodine tablets at UPZ (in Japanese). 2019. https://www.pref.saga.lg.jp/kiji00370394/index.html. Accessed 23 Apr 2020.

18. Cabinet Office, Government of Japan. Emergency response in the Genkai area. (in Japanese). 2019. https://www8.cao.go.jp/genshiryoku_bousai/keikaku/02_genkai.html. Accessed 23 Apr 2020.

19. Ojino M, Yoshida S, Nagata T, Ishii M. First Successful Pre-Distribution of Stable lodine Tablets Under Japan's New Policy After the Fukushima Daiichi Nuclear Accident. Disaster Med Public Health Prep. 2017. doi: https://doi.org/10.1017/dmp.2016.125.

20. World Health Organization. lodine thyroid blocking guidelines for use in planning and responding to radiological and nuclear emergencies. 2017. https://www.who.int/ionizing_radiation/pub_meet/iodine-thyroid-blocking/en/. Accessed 23 Apr 2020.

21. World Health Organization. Guidelines for iodine prophylaxis following nuclear accidents1999. 1999. https://www.who.int/ionizing_radiation/pub_meet/lodine_Prophylaxis_guide.pdf. Accessed 23 Apr 2020.

22. Cabinet Office, Nuclear Emergency preparedness of Japan. Protective measures in a nuclear accident -Sheltering to facilities where radiation protection measures have been taken (in Japanese). 2020.

23. https://www8.cao.go.jp/genshiryoku_bousai/pdf/02_okunai_zantei_r.pdf. Accessed 23 Apr 2020.

24. Jang M, Kim HK, Choi CW, Kang CS. Age-dependent potassium iodide effect on the thyroid irradiation by $131 \mathrm{I}$ and $133 \mathrm{I}$ in the nuclear emergency. Radiat Prot Dosimetry. 2008. doi: 10.1093/rpd/ncn068.

25. Verger P, Aurengo A, Geoffy B, Le Guen B. lodine kinetics and effectiveness of stable iodine prophylaxis after intake of radioactive iodine: a review. Thyroid. 2004. doi:

26. 1089/10507250152039082.

27. Agopiantz M, Elhanbali O, Demore B, Cuny T, Demarquet L, et al (2016) Paris Thyroid side effects prophylaxis in front of nuclear power plant accident. Ann Endocrinol February. 2016.doi:10.1016/j.ando.2015.12.003.

28. U.S. Department of Health \& Human Services Radiation Emergency Medical Management. the United States of America. 2020. Potassium iodide. . Accessed 23 Apr 2020. 
29. Ohba T, Tanigawa K, Liutsko L. Evacuation after a nuclear accident: Critical reviews of past nuclear accidents and proposal for future planning.

Environment Int. 2021. doi:

30. 1016/j.envint.2021.106379.

31. Laura R. Zwolinski, Martha Stanbury, Susan Manente. Nuclear power plant emergency preparedness: results from an evaluation of Michigan's potassium iodide distribution program. Disaster Med Public Health Prep.2013. doi:10.1001/dmp.2012.41.

32. Konishi E, Nagai T, Kobayashi K, Mitsumori Y, Ono W, et al (2016) Post-Fukushima radiation education for public health nursing students: a case study. Int Nursing Rev. 2016. doi:10.1111/inr.12244.

33. Yamada $\mathrm{Y}$, Orita M, Matsunaga $\mathrm{H}$, Yamaguchi T, Taira Y, et al. Risk perception regarding implementation of iodine thyroid blocking during a nuclear disaster of mothers living near a nuclear power station in Japan. Endocr J. 2021. doi:10.1507/endocrj.EJ20-0627.

\section{Tables}

Table 1. Characteristics of the guardians

\begin{tabular}{|c|c|c|c|}
\hline & & Nun & $\mathrm{r}$ \\
\hline Sex & male & 161 & 13.7 \\
\hline & Female & 1011 & 86.3 \\
\hline Age & $\begin{array}{l}<30 s \\
30 s \\
40 s\end{array}$ & $\begin{array}{l}121 \\
729 \\
315\end{array}$ & $\begin{array}{l}10.3 \\
62.2 \\
26.9\end{array}$ \\
\hline How many children under 18 years of age? & $\begin{array}{l}50 s< \\
1 \\
2\end{array}$ & $\begin{array}{c}7 \\
227 \\
493\end{array}$ & $\begin{array}{l}0.6 \\
19.4 \\
42.1\end{array}$ \\
\hline & 3 or more & 452 & 38.6 \\
\hline Do you wish to receive PDSI for your children? & Yes & 973 & 83.0 \\
\hline Have you participated in a nuclear emergency drill? & $\begin{array}{l}\text { Yes } \\
\text { Probably yes } \\
\text { Probably No }\end{array}$ & $\begin{array}{l}119 \\
629 \\
372 \\
52\end{array}$ & $\begin{array}{l}10.2 \\
53.7 \\
31.7 \\
4.4\end{array}$ \\
\hline Do you wish to participate in a lecture about the health effects of radiation exposure? & $\begin{array}{l}\text { Yes } \\
\text { Probably yes } \\
\text { Probably No }\end{array}$ & $\begin{array}{l}89 \\
587 \\
423\end{array}$ & $\begin{array}{l}7.6 \\
50.1 \\
36.1\end{array}$ \\
\hline Have you known of a public shelter to evacuate to during a nuclear emergency? & Yes & 487 & 41.6 \\
\hline Have you used SNS to collect information about radiation exposure? & Yes & 243 & $\begin{array}{l}30.4 \\
20.7\end{array}$ \\
\hline Had you known about SI before the study? & $\begin{array}{l}\text { No } \\
\text { Yes }\end{array}$ & $\begin{array}{l}929 \\
716\end{array}$ & $\begin{array}{l}79.3 \\
61.1\end{array}$ \\
\hline & No & 456 & 38.9 \\
\hline Do you wish prophylactic SI for your children during a nuclear emergency? & Yes & $\begin{array}{l}992 \\
180\end{array}$ & $\begin{array}{l}84.6 \\
15.4\end{array}$ \\
\hline Do you feel anxious about prophylactic SI for your children? & $\begin{array}{l}\text { Yes } \\
\text { Probably yes } \\
\text { Probably No }\end{array}$ & $\begin{array}{l}261 \\
580 \\
279\end{array}$ & $\begin{array}{l}22.3 \\
49.5 \\
23.8 \\
4.4\end{array}$ \\
\hline Do you think that pregnant women also should have prophylactic SI? & $\begin{array}{l}\text { Yes } \\
\text { Probably yes } \\
\text { Probably No } \\
\text { No }\end{array}$ & $\begin{array}{l}223 \\
653 \\
234 \\
62\end{array}$ & $\begin{array}{l}19.0 \\
55.7 \\
20.0 \\
5.3\end{array}$ \\
\hline Do you think that sheltering is useful to reduce the dose of radiation exposure? & $\begin{array}{l}\text { Yes } \\
\text { Probably yes } \\
\text { Probably No } \\
\text { No }\end{array}$ & $\begin{array}{l}199 \\
513 \\
368 \\
92\end{array}$ & $\begin{array}{l}17.0 \\
43.8 \\
31.4 \\
7.8\end{array}$ \\
\hline Do you think that SI can prevent exposure from all radionuclides? & $\begin{array}{l}\text { Yes } \\
\text { Probably yes } \\
\text { Probably No }\end{array}$ & $\begin{array}{r}24 \\
371 \\
617 \\
160\end{array}$ & $\begin{array}{l}2.0 \\
31.7 \\
52.6 \\
13.7\end{array}$ \\
\hline
\end{tabular}

Table 2. Characteristics of the guardians who wished to receive stable iodine (WRSI)

\begin{tabular}{|c|c|c|c|c|c|}
\hline & Unit & $\begin{array}{c}\text { Total } \\
\mathrm{n}=1172, \mathrm{n}(\%)\end{array}$ & $\begin{array}{c}\text { Group } 1 \\
\mathrm{n}=973, \mathrm{n}(\%)\end{array}$ & $\begin{array}{c}\text { Group } 2 \\
n=199, n(\%)\end{array}$ & $\mathrm{p}$ \\
\hline Age $<39$ years & Yes & $850(72.5)$ & $704(72.4)$ & $146(73.4)$ & 0.42 \\
\hline Have you participated in a nuclear emergency drill? & Yes & $215(18.3)$ & $183(18.8)$ & $32(16.1)$ & 0.42 \\
\hline Have you known of a public shelter to evacuate to during a nuclear emergency? & Yes & $487(41.6)$ & $407(41.8)$ & $80(40.2)$ & 0.37 \\
\hline Have you used SNS to collect information about radiation exposure? & Yes & $243(20.7)$ & $200(20.6)$ & $43(21.6)$ & 0.40 \\
\hline Do you feel anxious about prophylactic SI for your children? & Yes & $841(71.8)$ & $663(68.1)$ & $178(89.4)$ & $<0.01$ \\
\hline Do you think that pregnant women also should have prophylactic SI? & Yes & $876(74.7)$ & $804(82.6)$ & $72(36.2)$ & $<0.01$ \\
\hline Do you think that sheltering is useful to reduce the dose of radiation exposure? & Yes & $712(60.8)$ & $611(62.8)$ & $101(50.7)$ & $<0.01$ \\
\hline Do you think that SI can prevent exposure from all radionuclides? & Yes & 395 (33.7) & $364(37.4)$ & $31(15.6)$ & $<0.01$ \\
\hline
\end{tabular}


Note. Chi-squared tests. PDSI $=$ pre-distribution of stable iodine, $\mathrm{SI}=$ stable iodine, $\mathrm{SNS}=$ social network services. Group $1=$ want to receive PDSI, Group $2=$ not want to receive PDSI

Table 3. Results of the logistic regression analysis of guardians who wished to receive stable iodine (SI)

\begin{tabular}{llll}
\hline Variables & Reference & OR (95\%CI) & $\mathrm{p}$ \\
\hline Thought that pregnant women also should have prophylactic SI & Yes/No & $6.57(4.62-9.35)$ & $<0.01$ \\
Wish to participate in a lecture about the health effects of radiation exposure & Yes/No & $1.99(1.40-2.82)$ & $<0.01$ \\
\hline Thought that SI can prevent exposure from all radionuclides & Yes/No & $1.93(1.24-2.99)$ & $<0.01$ \\
\hline Had known about SI before the study & Yes/No & $1.91(1.35-2.71)$ & $<0.01$ \\
\hline Anxiety about prophylactic SI for their children & Yes/No & $0.33(0.20-0.55)$ & $<0.01$ \\
\hline
\end{tabular}

Note. Binominal logistic regression analysis, OR = odds ratio, 95\%CI $=95 \%$ confidence interval.

\section{Figures}

Figure 1

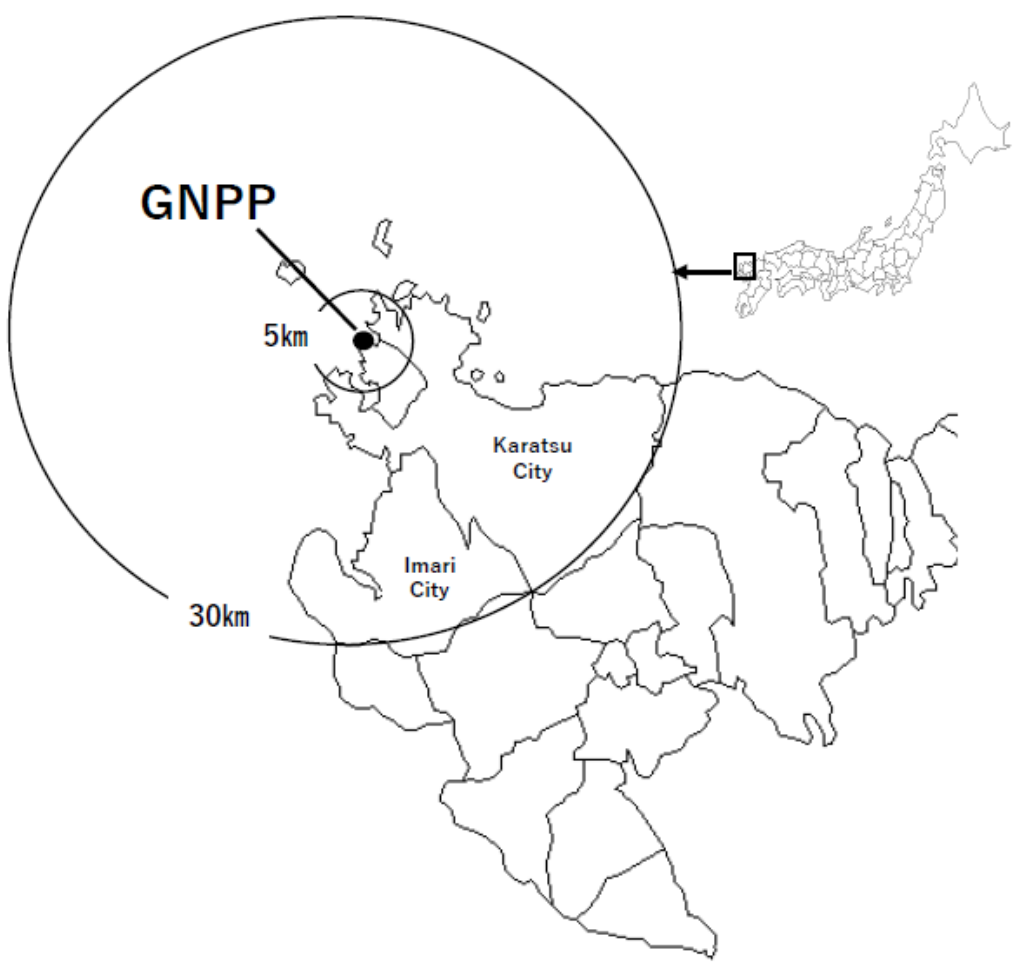

Figure 1

Location of the Genkai Nuclear Power Plant (GNPP) in Saga Prefecture, Japan. 
Figure 2
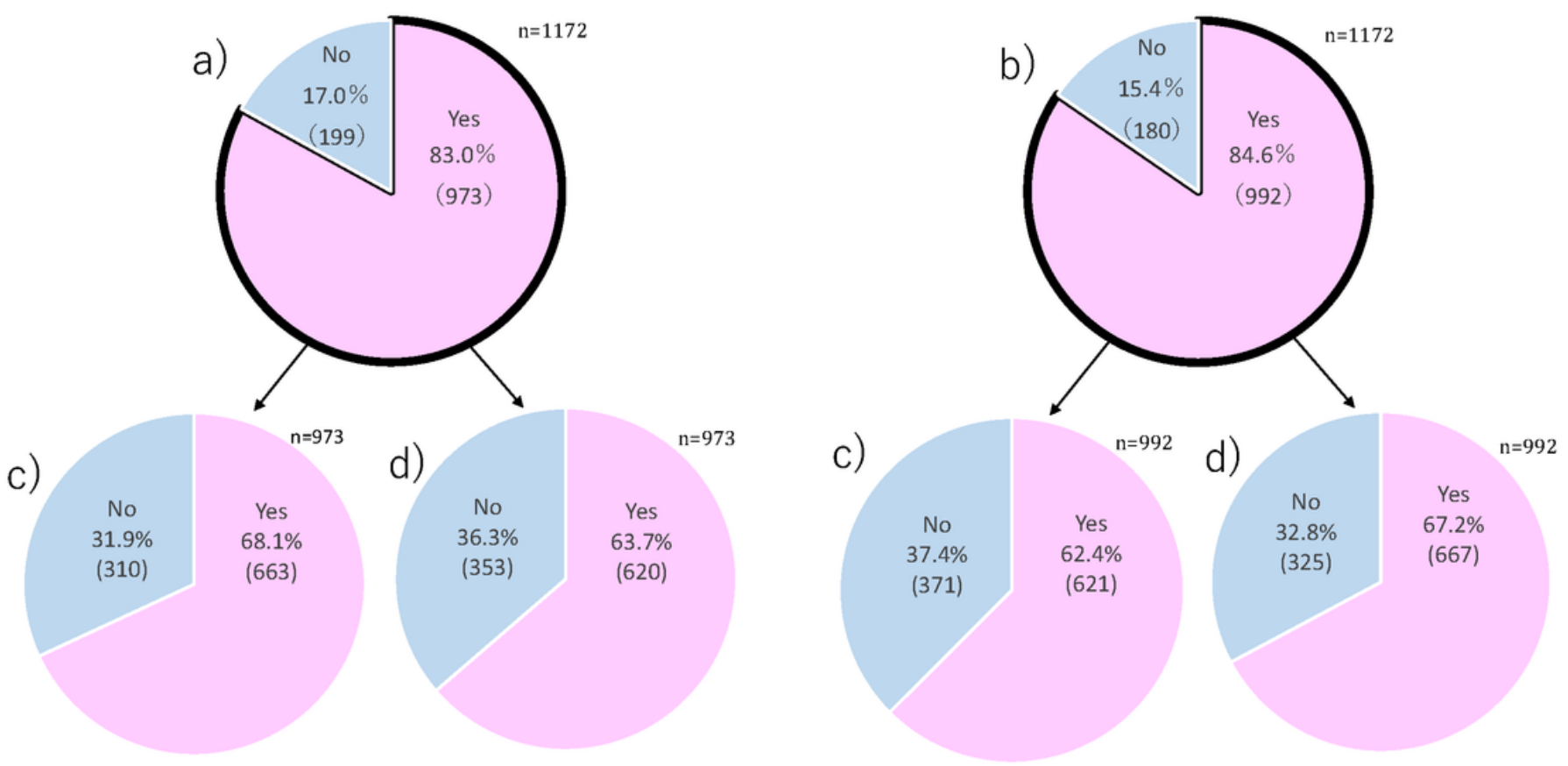

Figure 2

Awareness of SI among guardians living in the UPZ of the Genkai Nuclear Power Plant. a) Do you wish to receive PDSI for your children? b) Do you wish to have prophylactic SI for your children during a nuclear emergency? c) Had you known about SI before the study? d) Do you feel anxious about prophylactic SI for your children? Note. UPZ= Urgent Protective action planning Zone, SI= stable iodine. 
a)

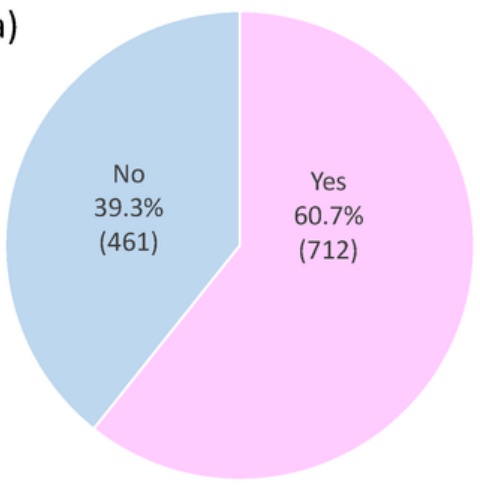

b)

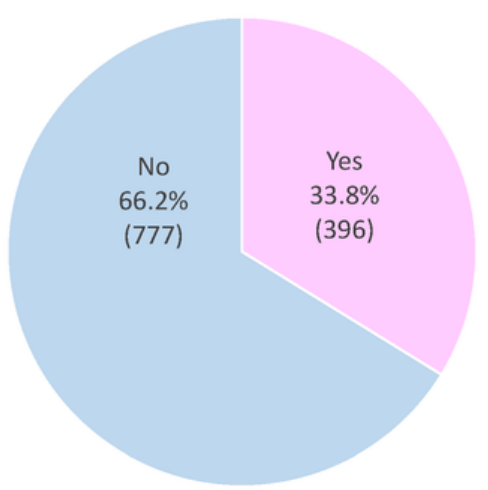

c)

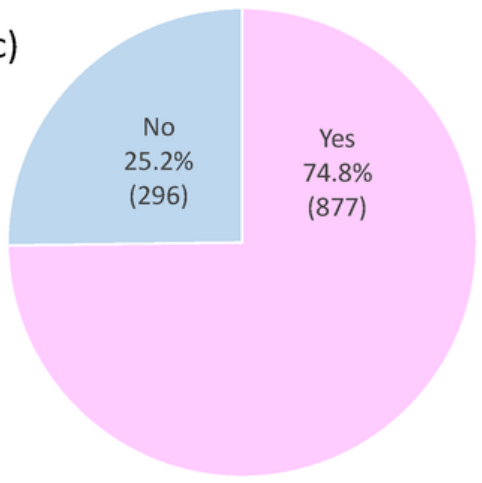

\section{Figure 3}

Perceptions about radiation protection and SI among the guardians. a) Do you think that sheltering is useful to reduce the dose of radiation exposure? b) Do you think that stable iodine can prevent exposure from all radionuclides? c) Do you think that pregnant women also should take prophylactic SI? Note. SI= stable iodine. 